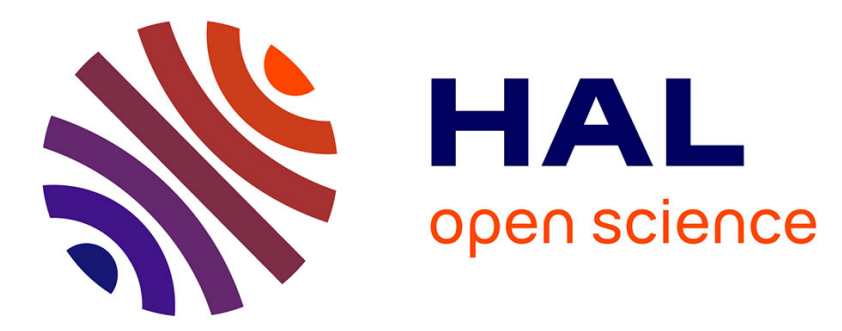

\title{
Siemens Smart CCD Detector Applied to Protein Crystallography with Synchrotron and Rotating Anode X-Ray Sources
}

E. Hovestreydt, J. Phillips, J. Chambers, J. Fait, M. Schuster, R. Sparks

\section{To cite this version:}

E. Hovestreydt, J. Phillips, J. Chambers, J. Fait, M. Schuster, et al.. Siemens Smart CCD Detector Applied to Protein Crystallography with Synchrotron and Rotating Anode X-Ray Sources. Journal de Physique IV Proceedings, 1996, 06 (C4), pp.C4-23-C4-32. 10.1051/jp4:1996403 . jpa-00254286

\section{HAL Id: jpa-00254286 https://hal.science/jpa-00254286}

Submitted on 1 Jan 1996

HAL is a multi-disciplinary open access archive for the deposit and dissemination of scientific research documents, whether they are published or not. The documents may come from teaching and research institutions in France or abroad, or from public or private research centers.
L'archive ouverte pluridisciplinaire HAL, est destinée au dépôt et à la diffusion de documents scientifiques de niveau recherche, publiés ou non, émanant des établissements d'enseignement et de recherche français ou étrangers, des laboratoires publics ou privés. 


\title{
Siemens Smart CCD Detector Applied to Protein Crystallography with Synchrotron and Rotating Anode X-Ray Sources
}

\author{
E. Hovestreydt, J. Phillips*, J. Chambers*, J. Fait*, M. Schuster* and R. Sparks* \\ Siemens AUT 37, P.O. Box 21 1262, 76181 Karlsruhe, Germany \\ * Siemens Analytical Instruments, 6300 Enterprise Lane, Madison, WI-53719-1173, U.S.A.
}

\begin{abstract}
The performance of the Siemens $\mathrm{CCD}$ detectors with $1 \mathrm{~K}$ and $2 \mathrm{~K}$ chips is evaluated using radiation from bending magnet beamlines at SSRL and NSLS and from a rotating anode source with three type of optics. Structure solution quality data is obtainable in short times for macromolecular and small molecule crystallography. General experiments, such as timeresolved powder diffraction and overlayer diffraction are also possible.
\end{abstract}

\section{INTRODUCTION}

The rapid success of the SMART system for small molecule crystallography using a Mo K $\alpha$ sealed tube source has prompted the investigation of its use for macromolecular crystallography. It was expected that SMART coupled to a high intensity, low divergence synchrotron radiation beam would perform well for this application. In particular, its advantages over other technologies presently used at synchrotron radiation sources are:

- short readout time (1.3s) improving data quality, observed resolution and data collection time (i.e. productivity of a beamline).

- better dynamic range and quantum efficiency

- "narrow data frames" giving better signal-to-background and allowing full 3D profiling.

To explore these possibilities tests were performed at SSRL beamline 1-5 AD and NSLS beamline X7B. These beamlines are both on bending magnets with tunable monochromators and focusing mirrors. Work has been performed on rotating anode sources coupled to three types of optics also and is reported here. This work is detailed in the summaries, tables and graphs below. 


\section{SSRL MEASUREMENTS SUMMARY}

At SSRL a 1K CCD was tested with a thin phosphor suitable for detection of long wavelengths. Data was sucessfully collected from a small molecule at nine wavelengths ( 0.855 to $2.06 \AA$ ) which spanned the tuning range of the mirror/monochromator system. This showed that $1.1 \AA$ would give the best intensities. A data set on a lysozyme crystal was obtained at $1.54 \AA$ for a direct comparison with data from the same crystal collected using a rotating anode. This indicated improvements in intensities of 10 at $1.54 \AA$ and 35 for $1.1 \AA$. Rocking curve widths were much narrower, an effect found with other samples and which can be exploited to give improved signal-to-background ( Refs. 1-3). Data was collected at $1.1 \AA$ on $231 \AA$ axis crystal ( $\beta$-2 Luciferase) with axis resolved at detector distance $100 \mathrm{~mm}$ and $\mathrm{d}$-spacing at the edge of the detector of $1.88 \AA$. High resolution rocking curve measurements on Thaumutin studied crystal growth in ground and space-grown crystals. The technique illustrates the parallelism of the synchrotron beam and the precision of the PLATFORM goniometer. Anomalous dispersion enhancement by choice of wavelengths close to the Fe $\mathrm{K}$ edge $(1.74 \AA)$ led to heavy atom location in a Patterson map. The sample was monoclinic Myoglobin and data collection took $2.7 \mathrm{hrs}$. Data to $1.9 \AA$ and $3.3 \% \mathrm{R}_{\mathrm{m}}$ rge were obtained.

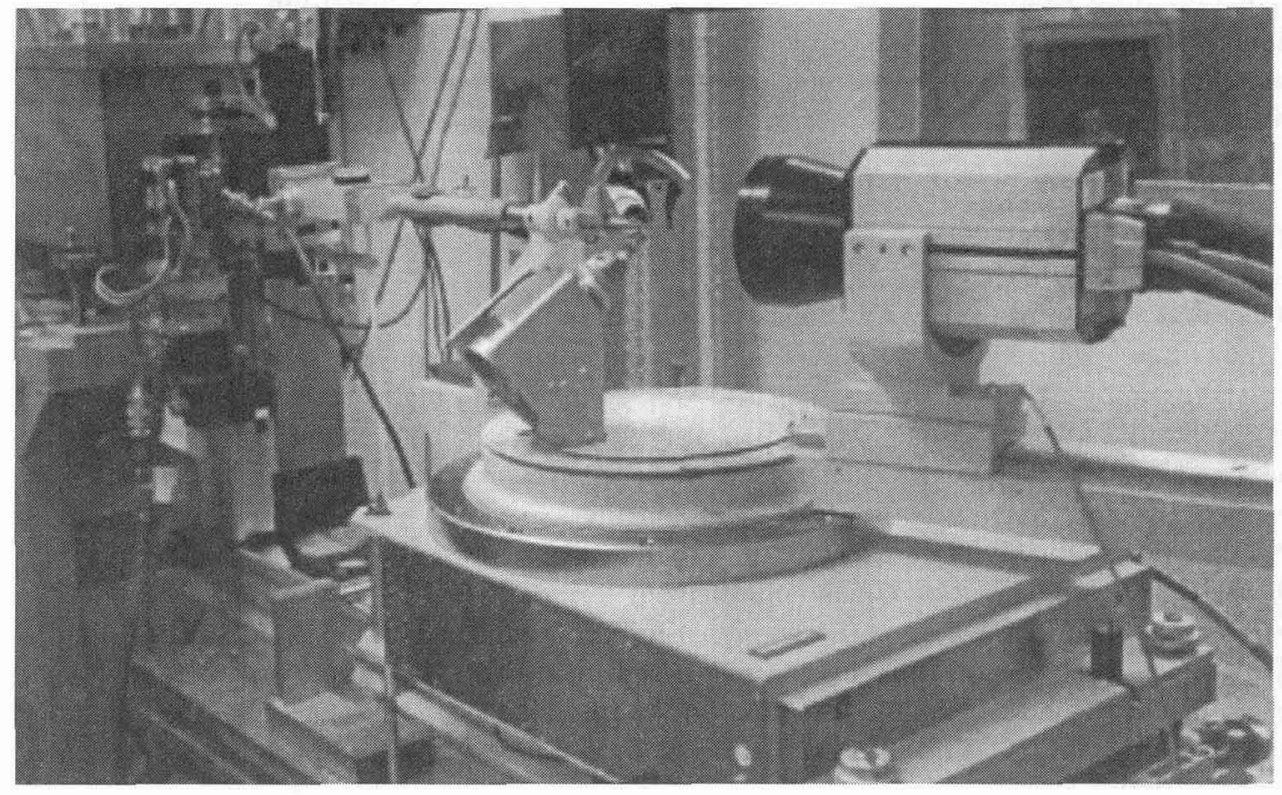

The small molecule data sets showed that the SMART system can efficiently detect $\mathrm{x}$-rays as low as $2.06 \AA$. A data set at $1.0 \AA$ was solved by direct methods (SHELXTL) with a total exposure for the data set of only 3.5 minutes. 


\section{NSLS MEASUREMENTS SUMMARY}

At NSLS the $2 \mathrm{~K}$ CCD system was used exclusively. Also the goniometer was set up with the $\omega-29$ axis horizontal, with a fast shutter to allow for short and accurate exposures and with provision for incident beam monitoring by the data collection software. Wavelengths close to $1 \AA$ were used exclusively. Data on lysozyme with $\mathrm{R}_{\text {sym }}$ of $7.2 \%$ to $1.5 \AA$ was obtained in 5.5 hrs. Data on $\alpha \beta$ luciferase, which has a $302 \AA$ axis (Ref. 5) was was obtained in $8.0 \mathrm{hrs}$ with $\mathrm{R}_{\text {sym }}$ of $13.6 \%$ to $3.4 \AA$. The system was also used for small molecule crystallography, solving a porphyrin, a zeolite and a carborane structure previously unsolved because of poor or small crystals. The system was also used for time-resolved powder diffraction and diffraction by multilayers on a macroscopic single crystal substrate.

\section{ROTATING ANODE MEASUREMENTS SUMMARY}

On a rotating anode various sets of optics were tested with the $1 \mathrm{~K} \mathrm{CCD.} \mathrm{A} 0.5 \times 1 \mathrm{~mm}$ focus loaded to $15 \mathrm{~kW}$ and a graphite monochromator gave data on lysozyme of $4.0 \% \mathrm{R}_{\mathrm{merge}}$ to $1.8 \AA$ resolution in $2 \mathrm{hrs}$. With double Franks mirrors (one $60 \mathrm{~mm}$ long, one $160 \mathrm{~mm}$ ) and a $.3 \times 3 \mathrm{~mm}$ focus loaded to $5 \mathrm{~kW}$ a similar data set gave an $\mathrm{R}_{\text {merge }}$ of $7.2 \%$ to $1.89 \AA$. With double graded multilayer monochromators (Ref. 4) and the same source a $2.9 \% R_{\text {merge }}$ to $1.7 \AA$ was obtained in $4.8 \mathrm{hr}$. Data from these latter two measurements were used to calculate a 6-fold increase in diffracted intensities from the mirror to the multilayer optics. With the multilayers a $2 \mathrm{~K} \mathrm{CCD}$ was also tested giving data to $6.1 \%$ to $1.6 \AA$. Data on $\beta-2$ Luciferase was obtained with $\mathrm{R}_{\mathrm{Sym}}$ of $8.0 \%$ to $2.6 \AA$.

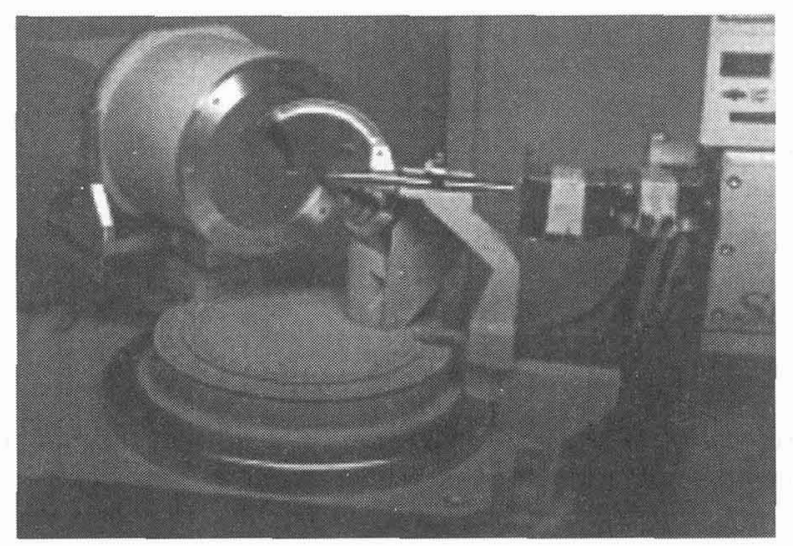

\section{SOFTWARE}

There have been recent attempts to standardize experimenter detector interfaces for protein crystallography at various synchrotron laboratories. The Siemens data collection software, with graphical user interface is demonstrated in the figures. 


\section{SMART 1K CCD Detector Characteristics}

- $1 \mathrm{~K}$ chip, $25 \times 25 \mathrm{~mm}$ on a side

- 2.5:1 fiberoptic taper permanently bonded to chip

- Patented method of matching fiber to surface of chip to maintain 1 to 2 micron consistent distance, custom epoxy bonding

- 64 x $64 \mathrm{~mm}$ square active area, equal to $4096 \mathrm{~mm}^{2}$

- $90 \mathrm{~mm}$ diameter phosphor, several choices, changeable Siemens custom phosphors, gadolinium oxysulfide

- Cooled by closed-cycle refrigerant to about $-50^{\circ}$

- Pixel resolution:

25 microns at the chip

60 microns at the detector face

- Readout 1024 x 1024 or 512 × 512 binned

- Readout time (512): 1.3 seconds; (1024): 5.2 seconds

- Digitization range, 19 bits $(524,288: 1)$

- Total system noise < single x-ray photon

- Automatic gain, 4:1

- Spatial uniformity factory calibration (fiducial plate)

- Intensity uniformity factory calibration (flood field)

- $<3 \% \mathrm{R}_{\text {sym }}$ on stable crystals demonstrates detector uniformity

\section{PLATFORM Goniometer}

$\begin{array}{lll}3 \text { axes } & & \\ \text { Speed } & 2 \vartheta & 1000^{\circ} / \text { minute } \\ & \omega & 1000^{\circ} \text { minute } \\ & \varphi & 2000^{\circ} \text { minute } \\ & \pm 0.0005^{\circ} \\ \text { Reproducibility } & & \text { Full } 360^{\circ} \\ \text { Max range } & 2 \vartheta & \text { Full } 360^{\circ} \\ & \omega & \text { Full } 360^{\circ} \\ & \varphi & 54.74^{\circ} \text { fixed }\end{array}$

Note that the detector is on a 28 arm so that it can be positioned at different 29 positions and that it can be moved along a dovetail to obtain various detector to crystal distances (up to 30 $\mathrm{cm}$ for standard arm). With these adjustments it is possible to collect data to any resolution for small or large unit cells at a wide range of $x$-ray wavelengths. Because the $c$-value is fixed at $54.74^{\circ}$ it is usually possible to collect a complete data set by rotating about $w$ at one or more positions of $\varphi$. Thus, no remounting of the crystal is necessary. 


\section{SMART 2K CCD Detector Characteristics}

- $2 \mathrm{~K}$ chip, $51 \times 51 \mathrm{~mm}$ on a side

- 1.9:1 fiberoptic taper permanently bonded to chip

- Patented method of matching fiber to surface of chip to maintain 1 to 2 micron consistent distance, custom epoxy bonding

- $96.5 \times 96.5 \mathrm{~mm}$ square active area equal to $9316 \mathrm{~mm}^{2}$

- $136 \mathrm{~mm}$ diameter phosphor, several choices, changeable Siemens custom phosphors, gadolinium oxysulfide

- Cooled by closed-cycle refrigerant to about $-50^{\circ}$

- Pixel resolution:

25 microns at the chip

48 microns at the detector face

- Readout $1024 \times 1024$ or $512 \times 512$ binned

- Readout time (512): 1.3 seconds; (1024): 5.2 seconds

- Digitization range, 19 bits $(524,288: 1)$

- Total system noise < single $\mathrm{x}$-ray photon

- Automatic gain, 4:1

- Spatial uniformity factory calibration (fiducial plate)

- Intensity uniformity factory calibration (flood field)

- $<3 \% \mathrm{R}_{\text {sym }}$ on stable crystals demonstrates detector uniformity

Software for single crystal experiments

SMART

Screen crystals via rotation

Measure rocking curves

Index reflections

Determine Bravais lattice

Refine unit cell parameters

Collect and display data (automatic and hands-on)

ASTRO

Simulate data collection strategies

Calculate percent completeness and redundancy

Display 3D image of goniometer, detector, data, axes

SAINT Integrate reflections with $3 \mathrm{D}$ profiling

Sort and filter data

Correct for crystal decay, $\mathrm{x}$-ray absorption

Average different data runs and/or different crystals

Compute statistical analyses

SHELXTL

Verify cell dimensions, Laue class, space group

Display data as reciprocal lattice layers

Calculate and contour Patterson maps

Full matrix least squares refinement, $\mathrm{F}^{2}$ constraints and restraints from known protein and nucleic acid structures, 5000 atoms 


\section{SSRL Data Sets}

\section{$\beta-2$ luciferase}

Unit cell dimensions $a=231.9 b=62.4 \mathrm{c}=62.6$; Space group $\mathrm{P} 22_{1} 2_{1}$

Frame width $=0.2^{\circ}$ Frame time $=14$ sec.; 527 frames

Total elapsed time $=3.2 \mathrm{hrs}$

Distance to detector $=10 \mathrm{~cm}$; Wavelength $=1.1 \AA$

Total unique reflections $=22630$

$\mathrm{R}_{\text {Sym }}=11.4 \%$ to $2.7 \AA$; $84.5 \%$ complete

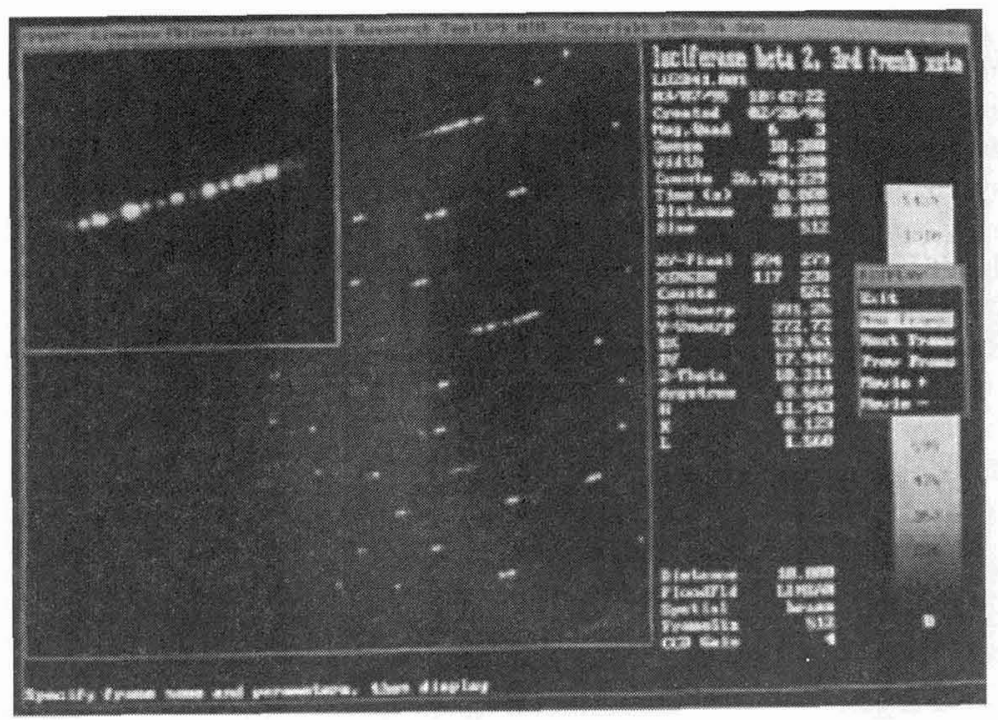

Met - myoglobin

Unit cell dimensions $a=34.8 \quad b=31.0 \quad c=64.5 \quad \beta=105.6^{\circ}$ Space group $P 2_{1}$

Frame width $=0.3^{\circ}$ Frame time $=7 \mathrm{sec}$. Distance to detector $=5.9 \mathrm{~cm}$

1st wavelength $=1.73770 \AA \quad 667$ frames; total elapsed time $=2.9$ hrs

Total unique reflections $=8610$; total reflections $=12308$

$\mathrm{R}_{\text {sym }}=3.8 \%$ to $1.9 \AA ; 76.6 \%$ complete

2nd wavelength $=1.74010 \AA \quad 667$ frames; total elapsed time $=2.9 \mathrm{hrs}$

Total unique reflections $=8558$; total reflections $=12266$

$\mathrm{R}_{\text {sym }}=4.5 \%$ to $1.9 \AA ; 77.0 \%$ complete

3rd wavelength $=1.77750 \AA$

667 frames; Total elapsed time $=2.7 \mathrm{hrs}$

Total unique reflections $=8069$; total reflections $=11600$

$\mathrm{R}_{\mathrm{Sym}}=3.3 \%$ to $1.9 \AA ; 78 \%$ complete 


\section{Thaumatin}

Unit cell dimensions $a=b=58.5 \quad c=151.6$; Space group $\mathrm{P}_{2}{ }_{2}{ }_{1} 2$

This was a study on crystal growth by looking at rocking curves. Two crystals of thaumatin were used, one grown on the Space Shuttle and the second grown on the ground. The second crystal was considerably smaller than the first. Rocking curves were obtained for both crystals by measuring a series of 50 frames of $0.02^{\circ}$ width for each crystal. The rocking curve peak widths (background to background) are about $0.2^{\circ}$ for each crystal. Both crystal show the characteistic split peak.

\section{NSLS Data Sets}

\section{Lysozyme}

Unit cell dimensions $a=b=79.1 \mathrm{c}=37.9$; Space group $\mathrm{P}_{3} 2_{1} 2$

Frame width $=0.15^{\circ}$ Frame time $=15 \mathrm{sec}$.; 667 frames

Total elapsed time $=5.5 \mathrm{hrs}$

Total number reflections $=80875 \quad$ Total unique reflections $=19439$

$\mathrm{R}_{\mathrm{Sym}}=7.2 \%$ to $1.5 \AA ; 97.7 \%$ complete

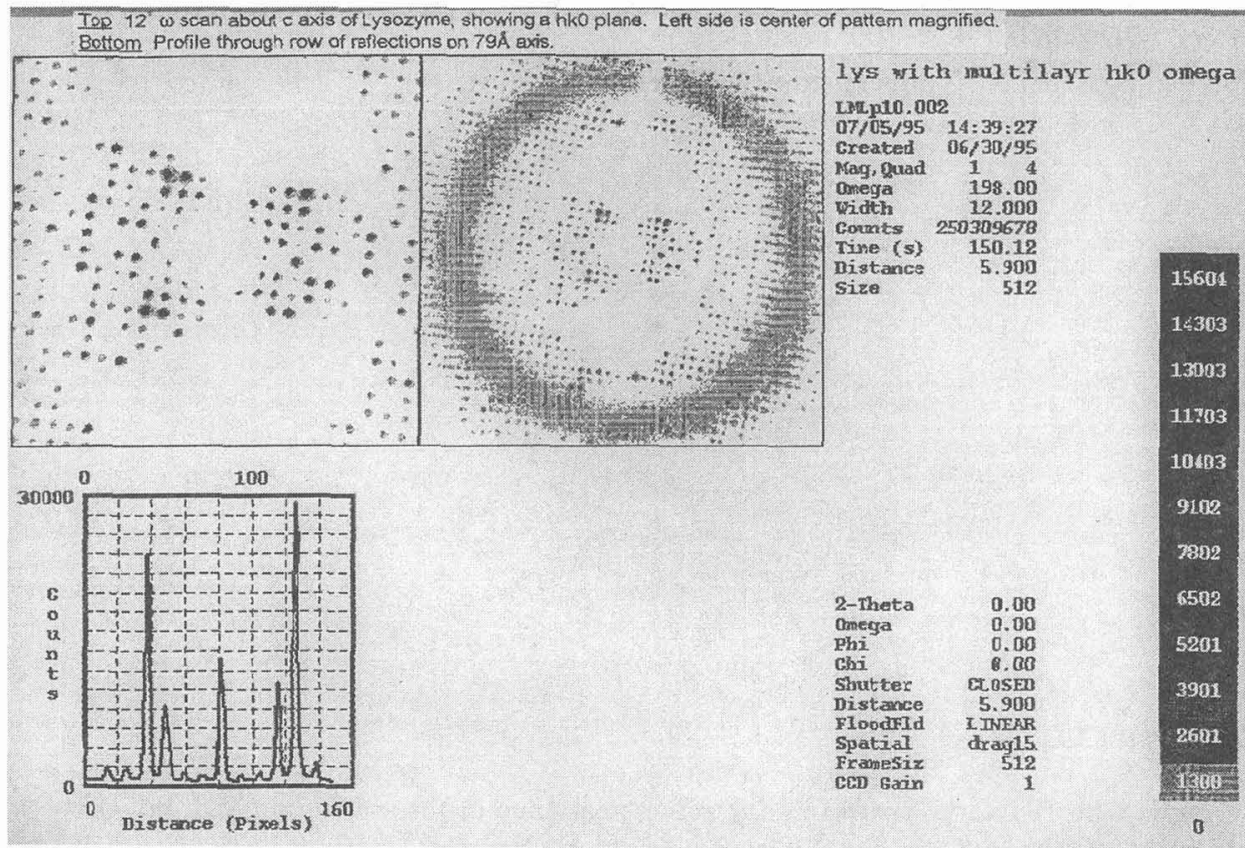




\section{$\underline{\alpha \beta \text { Luciferase }}$}

Unit cell dimensions $\mathrm{a}=59.9 \mathrm{~b}=112.7 \mathrm{c}=301.8$; Space group $\mathrm{P} 22_{1} 2_{1}$

Frame width $=0.2^{\circ}$ Frame time $=30$ sec.; 660 frames

Total elapsed time $=8.25 \mathrm{hrs}$

Total number reflections $=53825$

Total unique reflections $=26128$

$\mathrm{R}_{\text {sym }}=12.9 \%$ to $2.7 \AA ; 86 \%$ complete

$\underline{\mathrm{C}}_{2} \underline{\mathrm{N}}_{1} \underline{\mathrm{B}}_{10} \underline{\mathrm{H}_{15}}$

Unit cell dimensions $a=7.246 \quad b=18.429 c=18.140$

$\beta=92.482^{\circ} ;$ Space group $P 2 / n$

Frame width $=0.5^{\circ}$ Frame time $=15$ sec.; 720 frames (hemisphere of data)

Total elapsed time $=6 \mathrm{hrs}$

Total number reflections $=5134$

Total unique reflections $=2153$

$\mathrm{R}_{\text {sym }}=12.1 \%$ to $0.86 \AA ; 92.5 \%$ complete

Solved by SHELXTL direct methods and refined to $\mathrm{R} 1=0.068$

\section{$\underline{\text { Sodalite }}$}

Unit cell dimensions $a=8.8465$ Space group $\mathrm{Im}-3 \mathrm{~m}$

Frame width $=0.5^{\circ}$ Frame time $=45 \mathrm{sec}$.; 150 frames

Total elapsed time $=2.5 \mathrm{hrs}$

Total number reflections $=278$

Total unique reflections $=77$

$\mathrm{R}_{\text {sym }}=7.2 \%$ to $0.891 \AA ; 100 \%$ complete

Solved by SHELXTL direct methods and refined to $\mathrm{R} 1=0.041$

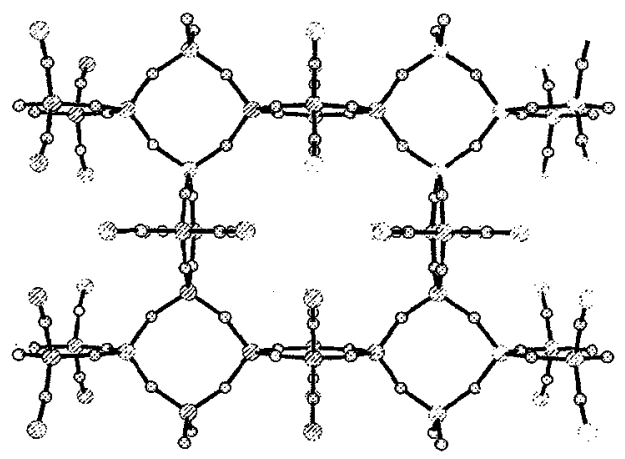

\section{Fe Silicide on Si(111)}

Sample with 10 overlayers shows diffraction peaks and diffuse scattering in a "powder scan" of 400 frames, $15 \mathrm{~s}$ and $0.1^{\circ}$ each. 


\section{Cu Rotating Anode Data Sets}

A two hour data set for lysozyme and a 24 hour data set for $\beta$ - 2 luciferase were collected using an $18 \mathrm{~kW} \mathrm{Cu}$ rotating anode generator with a graphite monochromator. The CCD detector was fitted with a phosphor designed to be efficient for a wavelength of $1.54 \AA$. The results are shown below.

\section{Lysozyme}

Unit cell dimensions $\mathrm{a}=\mathrm{b}=79.1 \mathrm{c}=37.9$; Space group $\mathrm{P} 4_{3}{ }_{2} 2$

Frame width $=0.3^{\circ}$ Frame time $=14.5$ sec.; 334 frames

Total elapsed time $=2$ hrs

Total number reflections $=27581 \quad$ Total unique reflections $=10872$

$\mathrm{R}_{\text {Sym }}=5.6 \%$ to $1.77 \AA ; 89 \%$ complete

\section{$\beta-2$ Luciferase}

Unit cell dimensions $a=231.9 \mathrm{~b}=62.4 \mathrm{c}=62.6$; Space group $\mathrm{P} 22_{1} 22_{1}$

Frame width $=0.25^{\circ}$ Frame time $=182 \mathrm{sec}$.; 480 frames

Total elapsed time $=24 \mathrm{hrs}$

Total unique reflections $=24255$

$\mathrm{R}_{\text {sym }}=12.9 \%$ to $2.7 \AA ; 86 \%$ complete

\section{Cu Rotating Anode with Göbel Mirrors Data Sets}

A two hour data set for lysozyme using a 1K SMART, a two hour data set for lysozyme using a 2K SMART, and a 2 hour data set for $\beta$ - 2 luciferase using a 2K SMART were collected using an $18 \mathrm{~kW} \mathrm{Cu}$ rotating anode generator with cross coupled Göbel mirrors. The CCD detector was fitted with a phosphor designed to be efficient for a wavelength of $1.54 \AA$. The results are shown below.

\section{Lysozyme, SMART $1 \mathrm{~K}$}

Unit cell dimensions $\mathrm{a}=\mathrm{b}=79.1 \mathrm{c}=37.9$; Space group $\mathrm{P}_{3}{ }_{2}{ }_{1} 2$

Frame width $=0.15^{\circ}$ Frame time $=21.9$ sec.; 617 frames

$\mathrm{R}_{\mathrm{sym}}=2.9 \%$ to $1.7 \AA ; 87.7 \%$ complete, Isotropic L.S. refinement $\mathrm{R}_{1}=14.9 \%$

\section{Lysozyme, SMART 2K}

Unit cell dimensions $a=b=79.1 c=37.9 ;$ Space group $P 4_{3} 2_{1} 2$

Frame width $=0.15^{\circ}$ Frame time $=21.9$ sec.; 617 frames

$\mathbf{R}_{\mathrm{sym}}=6.1 \%$ to $1.6 \AA ; 98.6 \%$ complete

\section{$\beta-2$ Luciferase}

Unit cell dimensions $\mathrm{a}=62.4 \mathrm{~b}=62.6, \mathrm{c}=231.9$; Space group $\mathrm{P} 22_{1} 2_{1} 2_{1}$

Frame width $=0.30^{\circ}$ Frame time $=124$ sec.; 400 frames

$\mathrm{R}_{\mathrm{Sym}}=8.0 \%$ to $2.6 \AA ; 85.0 \%$ complete 


\section{CONCLUSIONS}

These results demonstrate that the Siemens SMART CCD system can be used to collect good protein data with rotating anode sources and with synchrotron radiation. Crystals can be screened and an optimised data collection strategy started and concluded rapidly due to the fast readout time of the detector and the associated software. This leads to improved utilization of synchrotron beam time. Other types of experiment highlight the versatility of the system. Data collection on axes up to $300 \AA$ was demonstrated

Several modifications were made between the SSRL and NSLS experiments which enhanced the performance. In particular, vertical mounting ensured good intensities at high resolution for the lysozyme, small molecule and powder diffraction experiments.

Cross coupled Göbel mirrors give superior results on a rotating anode due to increased beam flux and reduced divergence. Refinement of lysozyme data collected with SMART and the mirrors gives a R1 of $14.9 \%$, and data collected for $\beta-2$ luciferase shows full resolution of the $231 \AA ̊$ axis.

\section{ACKNOWLEDGMENTS}

The experiments at beam line 1 - 5 at SSRL are part of an ongoing collaboration with Paul Phizackerley and the Biotechnology Group at Stanford. The experiments at NSLS X7B were performed with Jonathan Hanson and members of the Catalysis group of the Chemistry Department at Brookhaven National Laboratory. We thank Ivan Rayment of the Enzyme Institute of the University of Wisconsin, Madison for the lysozyme, $\alpha \beta$ luciferase and $\beta-2$ luciferase crystals. William Clegg, University of Newcastle and Kenneth Wade, University of Durham provided the carborane crystal. The sodalite study was with Joseph Pluth, University of Chicago and R. Broach, UOP. The multilayer diffraction was with Peter Eng, University of Chicago.

\section{REFERENCES}

[1] J.C. Phillips, J.A. Cerino, K.O. Hodgson, J. Appl. Cryst. 12 (1979) 592-600.

[2] M. Colapietro, G. Cappuccio, C. Marciante, A. Pifferi, R. Spagna, J.R. Helliwell, J. Appl. Cryst. 25 (1992) 192-194.

[3] R. Fourme, A. Ducruix, M. Ries-Kautt, B. Capelle, J. Synchrotron Rad 2 (1995) 136-142.

[4] M. Schuster, H. Göbel J. Appl. Phys. 28 (1995) A270-A275.

[5] A.J. Fisher, F.M. Raushel, T.O. Baldwin, I. Rayment, Biochemistry 12 (1995) 6581-6586. 